\title{
The Development of Atomic Game-Based Learning for Chemistry
}

Anisah Abdul Rahman, Ahmad Farid Najmuddin, Muhammad Faiz Abdullah, Ireen Munira Ibrahim, Siti Salihah Shaffie, Siti Rozanae Ismail

To Link this Article: http://dx.doi.org/10.6007/IJARBSS/v10-i11/8358

DOI:10.6007/IJARBSS/v10-i11/8358

Received: 21 September 2020, Revised: 23 October 2020, Accepted: 17 November 2020

Published Online: 22 November 2020

In-Text Citation: (Rahman et al., 2020)

To Cite this Article: Rahman, A. A., Najmuddin, A. F., Abdullah, M. F., Ibrahim, I. M., Shaffie, S. S., \& Ismail, S. R. (2020). The Development of Atomic Game-Based Learning for Chemistry. International Journal of Academic Research in Business and Social Sciences, 10(11), 1364-1372.

Copyright: (C) 2020 The Author(s)

Published by Human Resource Management Academic Research Society (www.hrmars.com)

This article is published under the Creative Commons Attribution (CC BY 4.0) license. Anyone may reproduce, distribute, translate and create derivative works of this article (for both commercial and non-commercial purposes), subject to full attribution to the original publication and authors. The full terms of this license may be seen at: http://creativecommons.org/licences/by/4.0/legalcode

Vol. 10, No. 11, 2020, Pg. 1364 - 1372

http://hrmars.com/index.php/pages/detail/IJARBSS

JOURNAL HOMEPAGE

Full Terms \& Conditions of access and use can be found at http://hrmars.com/index.php/pages/detail/publication-ethics 


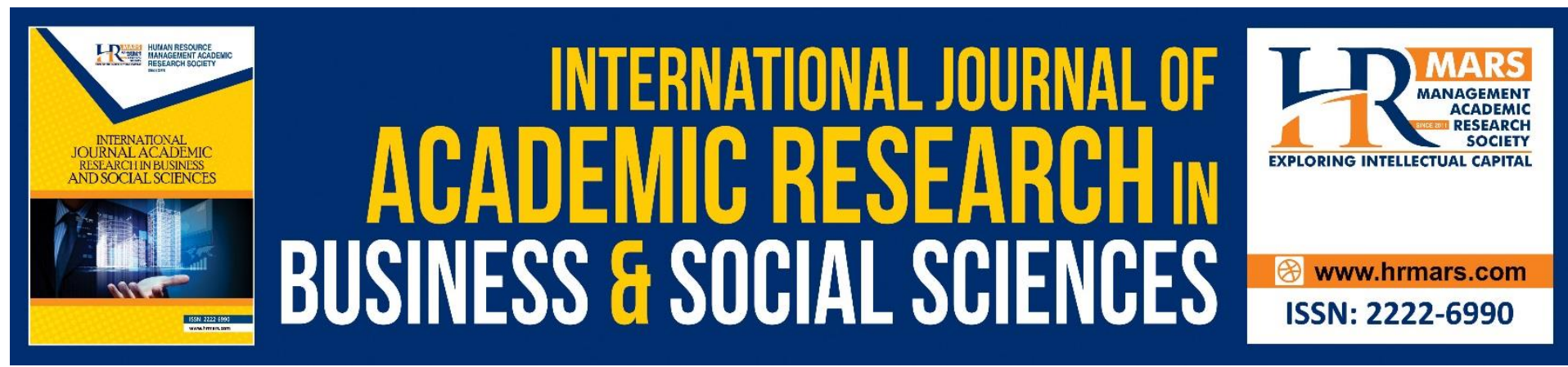

\title{
The Development of Atomic Game-Based Learning for Chemistry
}

\section{Anisah Abdul Rahman, Ahmad Farid Najmuddin, Muhammad Faiz Abdullah, Ireen Munira Ibrahim, Siti Salihah Shaffie, Siti Rozanae Ismail}

Faculty of Computer and Mathematical Sciences, Universiti Teknologi MARA, Perak Branch, Tapah Campus, Tapah Road, 35400 Perak, MALAYSIA

\begin{abstract}
The technology has become part of daily life. People use various of technologies to ease their work, to communicate, to get entertainment and even to educate. It innovates how people perform their daily tasks. In education, technology has become essential as a method of delivery and created a new pattern of learning. The students especially, they can access learning materials at the tip of their finger using smart phones, mobile computers, or tablets. They can choose where and when to learn at their convenience and deemed to be more effective than the traditional approach. The technology can create a whole new experience for the students to learn a specific topic, do quizzes, perform online discussions, watch tutorials in a more engaging environment. The purpose of this study is to present the steps taken to build a mobile application (app) prototype to learn structure of atom, named The Atomic. The design and development of the app prototype in this study is based on the Agile Game Development methodology (design, build, test, review, and launch phase). The prototype of the app contains the learning material that covers structure of atom topic running on Android platform to support teaching and learning activities in a classroom. The project combines the element of game and learning (Game-Based Learning, GBL). The player engagement and graceful failure element was applied in the project. By using a platformer setting for the game, it makes the learning to be more engaging when playing. With the use of Unity Game Engine, all features and components needed were implemented successfully. The game was given to the respective teachers for them to explore the contents, flows and functions of the app before it being released for use by the students. Feedbacks obtained from the teachers were gathered and documented for app's future enhancements.
\end{abstract}

Keywords: Chemistry, Agile Methodology, Game-Based Learning, Atom Structure, Interactive Learning.

\section{Introduction}

Chemistry is a study of an interactions between matter and energy. It is a way to nurture the young adults to understand and help to improve healthcare, conservation of natural resources and protection of environment. Due to the importance of the knowledge, chemistry has become a compulsory subject for every science stream student. Yet, many 
students had problems learning this subject, hard to understand theoretically, no visualization and eventually lead to less interest and motivation to learn and explore the subject (Wan Yunus \& Mat Ali, 2018). In order to increase students' motivation in learning chemistry, gamebased Learning ( $\mathrm{GBL}$ ) approach is used to create interactive learning responses in the subject matter. Game-Based Learning involving the games in the educational process, aiming to enhance learning activities (Trajkovik, Malinovski, Vasileva-Stojanovska, \& Vasileva, 2018). This is an opportunity to use these instruments to achieve educational and instructional objectives (Sayan, 2015).

GBL provide a medium where students can play and learn at the same time. Recent studies have considered Game-Based Learning as an educational tool to speed up the academic achievement motivation of elementary school students (Choi, Huang, Jeffrey, \& Baek, 2013; Sung, Hwang, Hung, \& Huang, 2012; Van Eck, 2006). Particularly, it will help students to learn chemistry in a different way as they learn interactively and actively. This kind of active learning will make the students engaged in their learning and increase understanding at the same time (Goss \& Griffiths, 2017). Scientific evidence also suggests that students' argumentation skills can be facilitated through GBL features and elements such as digital storytelling and computer-supported problem-solving (Şendağ \& Odabaşı, 2009).

Mobile learning indicates the use of mobile devices in which offering learning process to be easier and reachable everywhere (Bukharaev \& Wisam Altaher, 2018). Research found that the impact of mobile learning can be seen in several factors, the effectiveness of the mobile learning like how the information is presented, motivation of the students to engage with the subject and the effectiveness of learning mobility (Aslan, 2016; Zydney \& Warner, 2016). According to a study done by Mäyrä (2015), Daily use of the mobile application or their handset is about 50 times more per day. Consequently, the combination of mobile games and education innovate and create the application where the students can benefited the technology, entertainment and education at the same time (Vlachopoulos \& Makri, 2017). Hence, mobile game not only used as the medium for entertainment, but also for education in which the student can learn and gain more knowledge.

Yet, the mobile game content and genre are different according to the age and the subject matter. Each of the game has its own property and style as it may differently affect the players according to their age. A research shows that different age has different interest in game genre (Eichenbaum \& Kattner, 2015; Mughal, 2019). Therefore, choosing a suitable game genre for the project may impact how the students will react toward the project as well as how the students learn chemistry through game. This project developed a game with content in accordance with form 4 school chemistry subject in structure on atom. It is proposed to evaluate the level of understanding of the students in chemistry subject. The project will combine the concept of learning through mobile device and GBL approach and intended to make learning chemistry to be more interactive. This project mainly focuses on this genre as the student will be engaged in a 2D platform game. Therefore, in this project, the focus will be on this genre in which the students must control the character who runs and jumps onto platforms, floors, ledges, or other objects. The students may need to learn the basic of controlling the character in the game while applying their chemistry knowledge as they progress throughout the game 


\section{App Development}

Agile is an approach that is used to develop products (for example: games) using short iterations. The main idea is not to make the entire project from start to finish but to make small features in small periods of time for the current project. Agile method makes it possible to adjust the project plan with the result of each iteration (Ruonala, 2016):

- Each iteration is a short project.

- Uses "inspect and adapt" practice to adjust the objectives and measure progress.
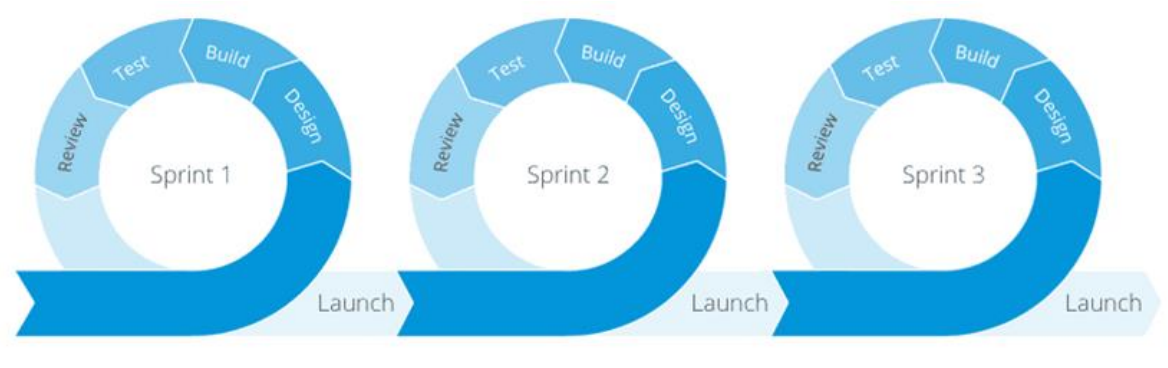

Figure 1. Stages of Agile Methodology (Sharma, 2018).

In agile development approach, planning is performed in every stage or iteration with small goals set to be achieved. Then the iteration follows with four steps as illustrated in Figure 1. When an iteration has completed with results, the review took place in the next iteration to conclude the previous iteration. This stage allows us to adjust the requirements to user needs and create new goals on what deliverables to be produced in the current iteration. Therefore, the use of this method promotes easier game development, able to cater what user wants in a game and it is tested on every iteration.

Unlike traditional approach, the development took place in 4 or 5 phases and the next phase can be started once the previous phase is completed. All phases are performed sequentially until the final goals are achieved at the end of the development. The problem with traditional approach is the user requirement is determined at the beginning of the development phase with only minimal amount of changes is allowed. In addition, users feedback process is performed in the final phase once the game development is completed. If the users require changes on the game, the developer must perform the development phases all over again, and it consumed time to readjust the requirements until a valid final product is completed.

The main difference of agile and traditional approach is where the goals are. In agile, small goals are set in every iteration to achieve the larger goals, while in traditional the development relies on the goals set at the final phase. In agile, users' feedback is important at every iteration, where every change is catered and tuned in into the development. The traditional development is heavily relied on the user requirements gathered at the beginning of the planning phase and is forced to stick with the requirements until the development is completed (Ruonala, 2016).

Agile approach is chosen due to its flexibility to handle changes, as game development requires a creative process that may change overtime. It allows users feedback and review in 
every iteration that enable the developer to adjust the project based on user needs, and finally produces a game that users want to play.

\section{Design Phase}

The design phase is the first phase in agile development approach, where all the elements in the game will be planned and design as shown in Figure 2 . This is very important in creating a project as this will make each of iteration to become clear thus easier to decide whether the step has achieving the main goal of the project or not. Brainstorming is the key in this phase. Before the start of each iteration, all parts of the development will need to be separated for a few iterations like the character design, level design and game play design. Then all the idea will be restructured and plan for the use during the build phase.

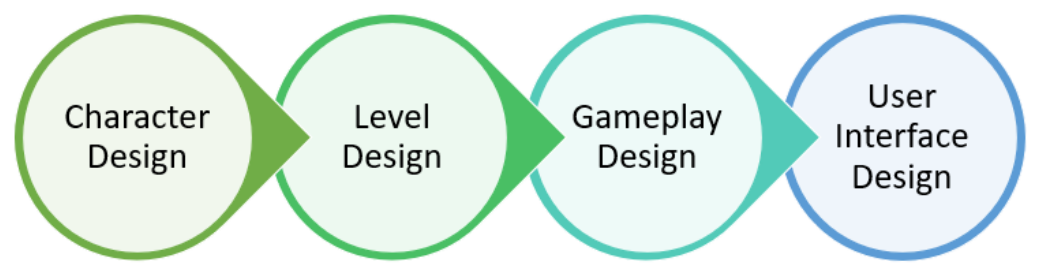

Figure 2. Stages of Design Phase

Character design is focusing on a character animation and how the movements of the characters take place. Level design discusses on the object in the game and how the floor or tile map will be position during the game play. Gameplay design will determine on how the user interact in the game and finally the users interface design which consists of steps in making the game to be accessed by the users.

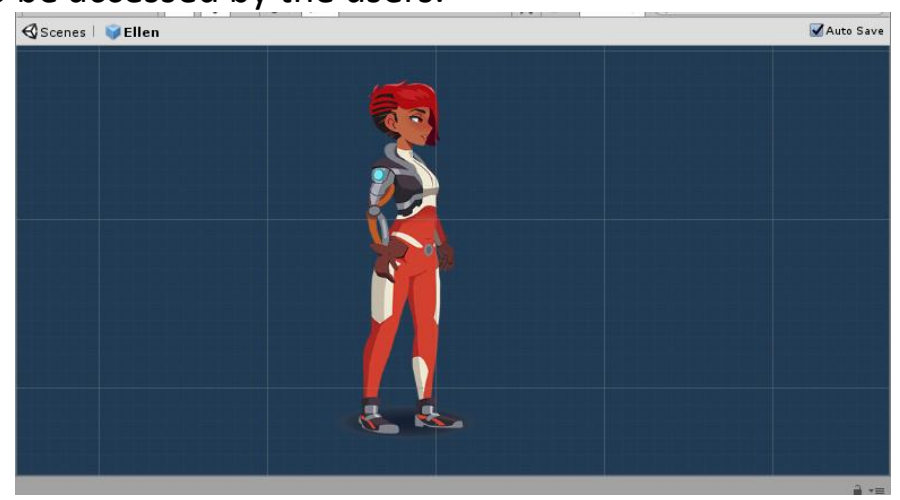

Figure 3. Ellen the main character

Figure 3 shows the main character in the game named Ellen. All the animation for the character is create by using the unity build in tool. There is also an enemy character in the game and the the enemy is controlled by script by setting it to act when there is a player nearby. When the player controls the character near to the green area of the enemies which is act as a field view of the enemies, the enemies will shoot at the position where the last player is detected on the green field as shown in Figure 4. 


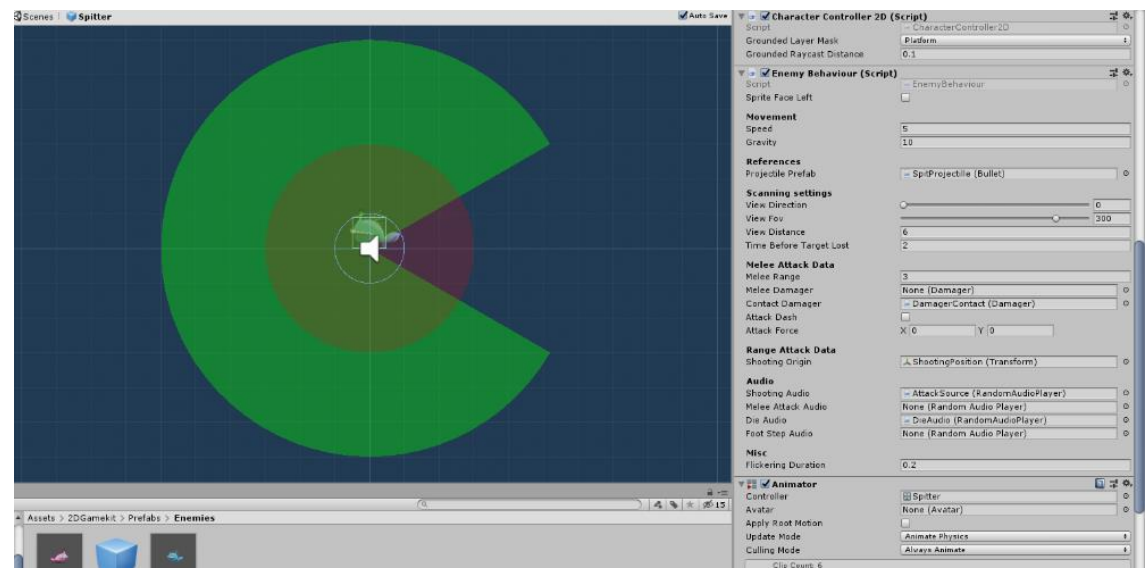

Figure 4. Enemy's field view

Figure 5 shows the full design of the map that is used in the game (level design), green line in the figure is "Tilemap collider 2D" which acts as a component to be collider between the object and the ground for the game. It makes the object in the game to be interactable while surface of the tilemap will act as ground for the object to be place.

Figure 6 depicts gameplay section in the game. The player needs to push the Pushable Box into the Acid Water which has Switch trigger that will make the Moving Platform to move once the accurate mass is achieved. Each of the Pushable box has different mass. This was made to coherent with the InfoPost nearby as it gives info to the player about the mass of object. Once the player pushes the Pushable box into the end of the platform, the player can see that both objects have different speed when it falls. The enemies will move around on the ground and attack the player once the player is on the enemy's field view. Player can destroy the enemies by hitting or shooting. If player fails to kill the enemies then enemies will attack the player. The players life will be minus one.

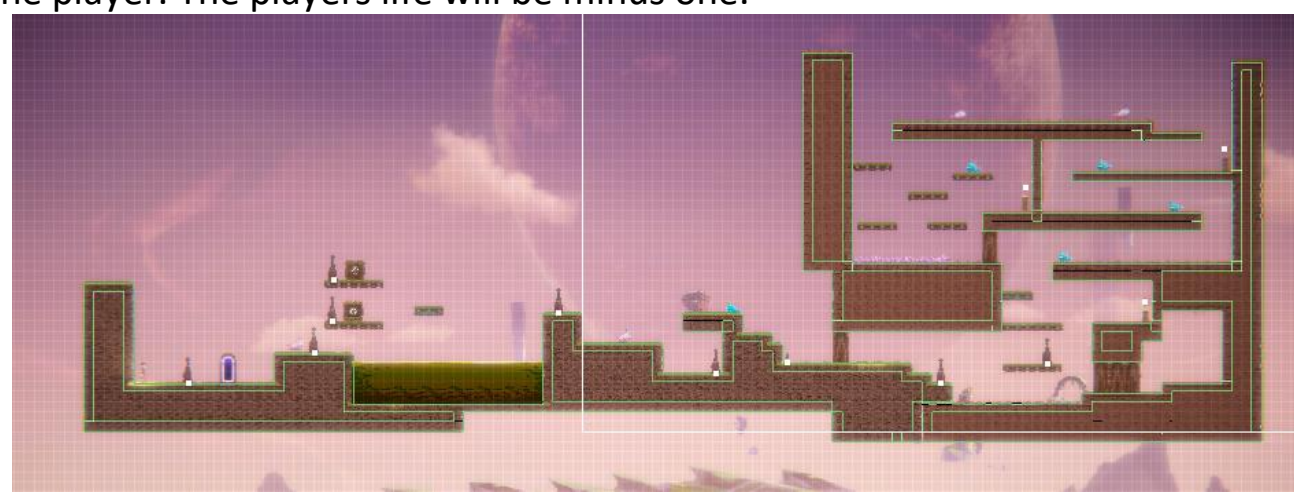

Figure 5. Tilemap for the game

When the set mass is achieved, the pressure pad will send instruction for the platform to move. Therefore, the player will be able to move to the next section, quiz section. The player needs to collect 3 keys and these keys will be used to unlock the door to the quiz section. Each key has different questions (question asked is about chemistry subject for secondary school) as shown in Figure 7 and each has its own mark and time limit. 


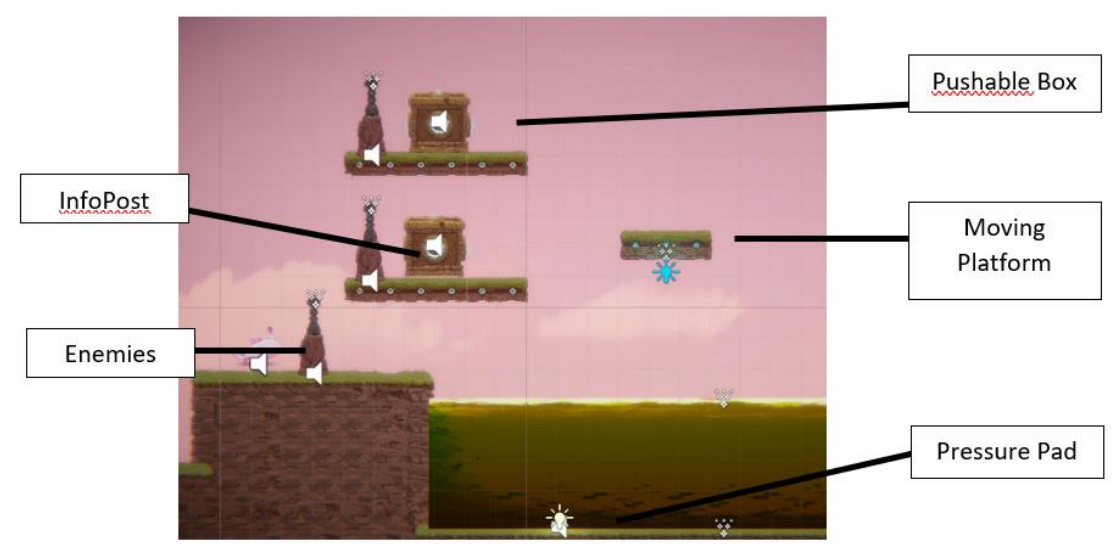

Figure 6. Gameplay section in the game

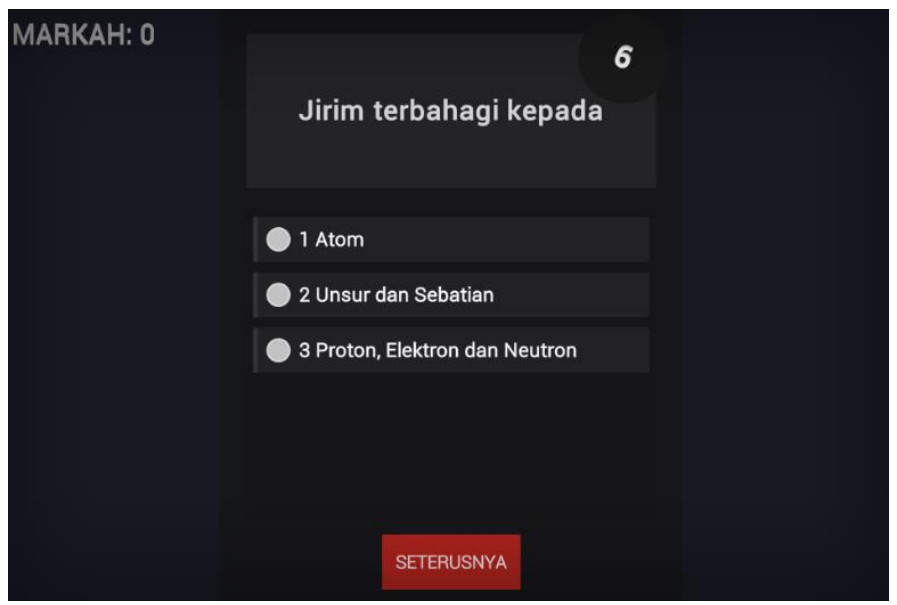

Figure 7. Quiz section in the game

Figure 8 shows the interface design for the main menu and game display. The message box is appeared because the user is at InfoPost so when the user moves forward then the message will disappear after one second. If the user keeps stay at InfoPost, the user can still read the message. The heart logo on the upper screen show the life of the character in game. While the opposite is the key that must be collected in the game.
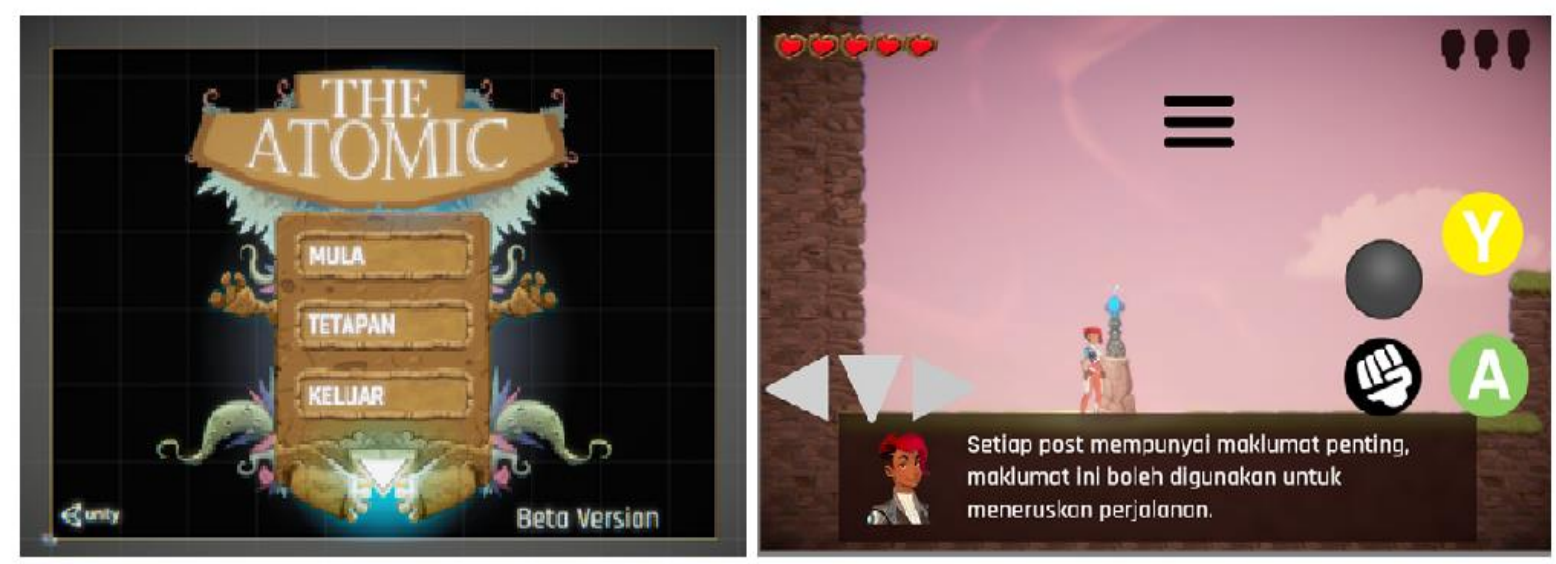

Figure 8. Game interface design in the game 


\section{Build, Test, Review and Launch Phase}

The game is built using the Unity engine and developed for an Android platform. The game is saved in APK format and this file can be installed and run in supported android devices. Mobile application testing is a process where app developed is tested for its functionality, usability, and consistency. Usability and Functionality Test is used to evaluate the app functionalities whether it is working as per requirements. This is to be done by the subject matter expert, which are the school's chemistry teachers. They will explore the app and give feedbacks on the interface, level of questions and difficulties, and the app's flow (review phase). The results from this activity will be included in the improvement phase before the app is tested on the students (launch phase).

\section{Conclusion}

This mobile game app has a great potential for students to learn chemistry's fundamental concepts, which it can promote motivation to learn the subject. However, the developed mobile game app still has plenty of room for improvements after being tested by the teachers (subject matter experts). Some of the improvements for future works are to improve the game flow with better gameplay, graphics, and performance quality, adding more game levels and variety of difficulties, improving user interactions towards the environment and more engaging interfaces. Integrating the technology and education is essential to provide instructiveness and more engaging environments for students to learn, as newer generations of students are technology oriented.

\section{Acknowledgment}

The authors would like to thank the Universiti Teknologi MARA Perak Branch and the Faculty of Computer and Mathematical Sciences of Tapah Campus for the supports and facilities provided in the completion of this project.

\section{Corresponding Author}

Ahmad Farid Bin Najmuddin is a Computer Science lecturer at Universiti Teknologi MARA Perak Branch, Tapah Campus, Tapah Road Perak, Malaysia. He can be contacted through Email: ahmad824@uitm.edu.my.

\section{References}

Anderson, C. A., \& Karen, E. D. (2002). Video games and aggressive thoughts, feelings and behavior in the laboratory and life. Journal of Personality and Social Psychology, 78(4), 772-790.

Aslan, S. (2016). Digital Educational Games: Methodologies for Development and Software Quality. Retrieved from https://vtechworks.lib.vt.edu/bitstream/handle/10919/73368 /Aslan_S_D_2016.pdf

Bukharaev, N., \& Wisam, A. (2018). Mobile Learning Education Has Become More Accessible. American Journal of Computer Science and Information Technology, 05(02), 3-7. https://doi.org/10.21767/2349-3917.100005

Choi, B., Huang, J., Jeffrey, A., \& Baek, Y. (2013). Development of a scale for fantasy state in digital games. Computers in Human Behavior, 29(5), 1980-1986.

Eichenbaum, A., \& Kattner, F. (2015). Journal of Addictive Rehabilitation the Role of Game Genres and the Development of Internet Gaming Disorder in School- Aged Children. Journal of Addictive Behaviors, Therapy \& Rehabilitation. 4(3), 1-7. https://doi.org/ 
10.4172/2324-9005.100141.

Goss, P., Sonnemann, J., \& Griffiths, K. (2017). Engaging students: creating classrooms that improve learning. Retrieved from http://www.grattan.edu.au/.

Kerthyayana, M. (2018). The Design and Game Mechanic of Combined Game Application Prototype for Learning Social Business. Procedia Computer Science, 135, 52-59. https://doi.org/10.1016/j.procs.2018.08.149

Mayra, F. (2015). Mobile Games the Expanding Field of Mobile Gaming. In the International Encyclopedia of Digital Communication and Society (eds P.H. Ang and R. Mansell). Retrieved from https://doi.org/10.1002/9781118290743.wbiedcs014

Ruonala, H. (2016). Agile Game Development: A Systematic Literature Review (Unpublished master's dissertation). Department of Computer Science, University of Helsinki

Sayan, H. (2015). The effects of computer games on the achievement of basic mathematical skills. Educational Research and Reviews, 10(22), 2846-2853.

Serkan, S. (2009) Effects of an online problem-based learning course on content knowledge acquisition and critical thinking skills. Journal of Computers \& Education, 53 (1) 132-141.

Sharma, A. (2018). Reasons Why We Trust Agile for Our Mobile App Development Process. Retrieved from https://appinventiv.com/blog/reasons-why-we-trust-agile-for-ourmobile- app-development-process/

Mughal, H. A. (2019). Support at Work and its Relationship with Employee Performance: Critical Insights for Early Scholars. Annals of Contemporary Developments in Management \& HR (ACDMHR), 1(3), 16-21.

Trajkovik, V., Malinovski, T., Vasileva-Stojanovska, T. \& Vasileva, M. (2018). Traditional games in elementary school: Relationships of student's personality traits, motivation, and experience with learning outcomes. PloS One, 13(2), 172-202. https://doi.org/10.1371/journal.pone.0202172.

Vlachopoulos, D., \& Makri, A. (2017). The effect of games and simulations on higher education: a systematic literature review. International Journal of Educational Technology in Higher Education, 14(1), 22. https://doi.org/10.1186/s41239-017-0062-1.

Wan Yunus, F., \& Mat Ali, Z. (2018). Attitude Towards Learning Chemistry Among Secondary School Students in Malaysia. Asian Journal of Behavioral Studies, 3(9), 63. https://doi.org/10.21834/ajbes.v3i9.61. 